\title{
Clinical features and outcome of Guillain- Barre syndrome in Saudi Arabia: a multicenter, retrospective study
}

\author{
Mohammed H. Alanazy ${ }^{1 *}$, Sawsan S. Bakry ${ }^{1}$, Afnan Alqahtani ${ }^{1}$, Norah S. AlAkeel², Naael Alazwary ${ }^{3}$, \\ Afag M. Osman ${ }^{4}$, Rania A. Mustafa ${ }^{4}$, Talal M. Al-Harbi ${ }^{5}$, Sameeh O. Abdulmana ${ }^{5}$, Aimee C. Amper, \\ Yousef Aldughaythir ${ }^{6}$, Abdulrahman S. Ali ${ }^{6}$, Seraj Makkawi ${ }^{7,8,9}$, Alaa Maglan', Loujen Alamoudi ${ }^{7}$, \\ Feras Alsulaiman ${ }^{10}$, Majed Alabdali ${ }^{10}$, Aysha A. AlShareef ${ }^{11}$, Ahmad R. Abuzinadah ${ }^{11}$ and Ahmed K. Bamaga ${ }^{12}$
}

\begin{abstract}
Background: Guillain-Barre syndrome (GBS) is an inflammatory polyradiculoneuropathy characterized by rapidly evolving weakness and areflexia, reaching nadir within 4 weeks. Data on the characteristic of GBS in Saudi Arabia are limited. This study aimed to describe the clinical, electrophysiological, and laboratory characteristics and outcome of a multicenter cohort of patients with GBS.

Methods: This is a retrospective multicenter nationwide study. Patients who had GBS, identified through Brighton Criteria, between January 2015 and December 2019 were included. Data collected included demographics, clinical features, cerebrospinal fluid profile, reported electrophysiological patterns, treatment, and outcome. Reported GBS subtypes were compared using chi-square, Fisher's exact, or Mann-Whitney $U$ tests, as appropriate.
\end{abstract}

Results: A total of 156 patients with GBS were included (men, 61.5\%), with a median age of 38 (interquartile range, 26.25-53.5) years. The most commonly reported antecedent illnesses were upper respiratory tract infection (39.1\%) and diarrhea (27.8\%). All but two patients (98.7\%) had weakness, 64.1\% had sensory symptoms, $43.1 \%$ had facial diplegia, 33.8\% had oropharyngeal weakness, 12.4\% had ophthalmoplegia, and 26.3\% needed mechanical ventilation. Cytoalbuminological dissociation was observed in $69.1 \%$ of the patients. GBS-specific therapy was administered in $96.8 \%$ of the patients, of whom $88.1 \%$ had intravenous immunoglobulin, and $11.9 \%$ had plasmapheresis. Approximately half of the patients were able to walk independently within 9 months after discharge, and a third regained the ability to walk independently thereafter. Death of one patient was caused by septicemia. Acute inflammatory demyelinating polyradiculoneuropathy was the most commonly reported GBS subtype (37.7\%), followed by acute motor axonal neuropathy (29.5\%), and acute motor-sensory axonal neuropathy (19.2\%).

Conclusion: The clinical and laboratory characteristics and outcome of GBS in the Arab population of Saudi Arabia are similar to the international cohorts. The overall prognosis is favorable.

Keywords: Acute inflammatory demyelinating polyradiculoneuropathy, Acute motor axonal neuropathy, Acute motor-sensory axonal neuropathy, Guillain-Barre Syndrome, Intravenous immunoglobulin, Saudi Arabia

*Correspondence: mohalanazy@ksu.edu.sa

1 Division of Neurology, Department of Internal Medicine, King Saud University Medical City and College of Medicine, King Saud University, Riyadh, Saudi Arabia

Full list of author information is available at the end of the article

\section{Background}

Guillain-Barre syndrome (GBS) is the most common cause of acute neuropathy worldwide, affecting approximately $1-2$ per 100,000 person-years [1]. It has first been 
described in 1916, and since then, more cases have been recognized, leading to the recognition that GBS comprises a wide spectrum of symptoms with different clinical outcomes [2]. Therefore, it has been categorized into different subtypes based on clinical, pathophysiological, and electrophysiological findings. The most common GBS subtypes include acute inflammatory demyelinating polyradiculoneuropathy (AIDP), acute motor axonal neuropathy (AMAN), and acute motor-sensory axonal neuropathy (AMSAN) [3]. Such classification has a diagnostic and prognostic value with AIDP variant having a favorable prognosis compared to the other two subtypes [4].

Previous studies have revealed regional variations in the prevalence of different subtypes of GBS [5]. In North America and Europe, AIDP has been reported as the predominant subtype [5], whereas the axonal subtype constituted only a small percentage of GBS cases. The contribution of the axonal subtype is higher in Northern China, Japan, and South America [6]. Data on GBS from Arab countries are limited [7]. One study in Kuwait analyzed 41 patients with GBS and found AIDP to be the most common subtype [8]. Another study from Iran reported AMSAN to be the predominant subtype among its local study population [9]. A single-center study conducted in Saudi Arabia did not provide data on GBS subtypes [10]. It is essential to determine the regional prevalence of GBS subtypes and understand their pathophysiology, which may eventually aid in developing a GBS subtype-targeted immune therapy.

This nationwide multicenter retrospective study aimed to highlight the clinical, laboratory, and electrophysiological characteristics and outcome in adult patients with GBS in Saudi Arabia and compare these parameters between GBS subtypes and our data to the international studies.

\section{Methods}

\section{Study design}

This is a retrospective multicenter study that included patients diagnosed with GBS between January 2015 and December 2019. Eight tertiary centers across the country participated in the study: four from the Central region (Riyadh), two from the Eastern region (Khobar and Dammam), and two from the Western region (Jeddah). The study was approved by the institutional review board at King Saud University and all other participating centers (Security Forces Hospital, Prince Sultan Military Medical City, King Fahad Medical City, King Fahad Specialist Hospital-Dammam, King Fahad Hospital of the University, King Saud Bin Abdulaziz University for Health Sciences, King Abdulaziz University). The need for informed consent was waived by all the participating centers.

\section{Study population}

Patients aged 18 years or more with GBS were identified through the electronic health system and/or electrophysiology database in each center. The inclusion criteria were adopted from the previously validated Brighton criteria, [11, 12] and included (1) acute or subacute flaccid weakness involving lower and/or upper limbs; (2) monophasic disease, reaching nadir of weakness between $12 \mathrm{~h}$ and 4 weeks; and at least one of the following: (a) hyporeflexia or areflexia in the weak limbs, (b) cytoalbuminological dissociation defined as the combination of cerebrospinal fluid (CSF) protein level $>0.45 \mathrm{~g} / \mathrm{L}$ and cell count $<50$ cells/ $\mu \mathrm{l}$, and (c) the reported electrophysiological features are compatible with a subtype of GBS. We accepted the subtype classification documented by the treating neurologists/neuromuscular specialists, because the lack of availability of electrophysiological raw data in most centers hindered our ability to confirm subtype classification. We allowed relative preservation of deep tendon reflexes in otherwise typical GBS presentations as has been described in a minority of patients [12-14]. We included patients who presented with the classical triads of Miller-Fisher syndrome (MFS): ataxia, ophthalmoplegia, and areflexia. The exclusion criteria were (1) progressive weakness for $>8$ weeks, (2) CSF cell count $\geq 50$ cells/ $\mu$ l, (3) onset of post-bariatric surgery, and (4) symptoms explained by an alternative diagnosis.

\section{Study variables}

In addition to demographic variables, we collected the following GBS variables: antecedent event type and time before onset, clinical features, time of symptom onset, forced vital capacity (FVC) at admission, reported electrophysiological classification (AIDP, AMAN, AMSAN, equivocal, and inexcitable), radiological features, CSF profile, therapy received, admission to an intensive care unit (ICU), mechanical ventilation, tracheostomy, duration of ICU stay, duration of hospitalization, and ability to walk at follow-up.

\section{Analysis}

Continuous variables were presented as median and interquartile range (IQR). Nominal variables were presented as counts and proportions. A chi-square test or Fisher's exact test was used to assess differences in binomial variables between GBS subtypes, as appropriate. A Mann-Whitney U test was used to assess differences in continuous variables between GBS subtypes. A two-sided $P$-value $<0.05$ was considered statistically significant. For multiple comparisons, a Bonferronicorrected $P$-value was calculated by multiplying the 
$P$-value with the number of comparisons conducted. Data were analyzed using the software SPSS (version 23, Chicago, IL).

\section{Results}

Initial screening revealed 169 patients, of whom 13 were excluded for the reason of not meeting the inclusion criteria or due to the presence of a mimicking disease and 156 patients were included in the study (96 [61.5\%] were men, and 60 [38.5\%] were women). Demographic and clinical characteristics of the patients with GBS are shown in Table 1. The median age was 38 (IQR 26.2553.5) years. Approximately, half of the patients (51.9\%)

Table 1 Demographic and clinical characteristics of patients with GBS at the time of admission

\begin{tabular}{|c|c|}
\hline Variable & $\mathrm{N}(\%)$ or median (IQR) \\
\hline Age, years & $38(26.25-53.5)$ \\
\hline Male: female & 1.6: 1 \\
\hline Antecedent illness ${ }^{a}$ & $101 / 133(75.9)$ \\
\hline URTI & $52 / 133(39.1)$ \\
\hline Diarrhea & $37 / 133(27.8)$ \\
\hline Surgery & $6 / 133(4.5)$ \\
\hline Others $^{\mathrm{b}}$ & $6 / 133(4.5)$ \\
\hline \multicolumn{2}{|l|}{ Seasonal distribution } \\
\hline Winter & $36 / 119(30.3)$ \\
\hline Spring & $32 / 119(26.9)$ \\
\hline Summer & $19 / 119(16.0)$ \\
\hline Autumn & $32 / 119(26.9)$ \\
\hline \multicolumn{2}{|l|}{ Clinical features at admission ${ }^{c}$} \\
\hline Weakness & 154/156 (98.7) \\
\hline Sensory disturbance & $100 / 156(64.1)$ \\
\hline Facial diplegia & $66 / 153(43.1)$ \\
\hline Oropharyngeal weakness & $52 / 154(33.8)$ \\
\hline Ophthalmoplegia & 19/153 (12.4) \\
\hline Dyspnea & $40 / 154(26.0)$ \\
\hline Ataxia & $2 / 154(1.3)$ \\
\hline Areflexia or hyporeflexia & 133/149 (89.3) \\
\hline Sensory (small fiber) involvement & $55 / 134(41.0)$ \\
\hline Sensory (large fiber) involvement & $23 / 117(19.7)$ \\
\hline Urinary retention & $2 / 156(1.3)$ \\
\hline Autonomic instability & $11 / 156(7.1)$ \\
\hline Able to walk independently at admission & $56 / 151(37.1)$ \\
\hline ICU admission ${ }^{d}$ & $52 / 156(33.3)$ \\
\hline Mechanical ventilation & $41 / 156(26.3)$ \\
\hline Tracheostomy & 25/156 (16.0) \\
\hline
\end{tabular}

${ }^{\text {a }}$ Median time before onset $=12$ (7-14) days

${ }^{\mathrm{b}} 2$ had fever; 1 had pneumonia; 1 had pyelonephritis; 1 had diabetic ketoacidosis; 1 was postpartum

${ }^{c}$ Median time from onset $=6(3-12)$ days

${ }^{\mathrm{d}}$ Duration of ICU stay $=17.5(7.5-34.5)$ days were aged $18-39$ years ( 57 men, 24 women), $29.5 \%$ were aged $40-59$ years ( 24 men, 22 women), and $18.6 \%$ were aged $\geq 60$ years ( 15 men, 14 women).

\section{Clinical features}

Approximately three-fourths of the patients had an antecedent event, with upper respiratory tract infection (URTI) being the most common antecedent infection, followed by diarrhea (Table 1). All but two patients (98.7\%) had weakness at admission, $64.1 \%$ had sensory symptoms, $43.1 \%$ had facial diplegia, $33.8 \%$ had oropharyngeal weakness, and $12.4 \%$ had ophthalmoplegia. The GBS clinical presentation was the classic sensorimotor form in $100(64.1 \%)$ patients. Fifty-four patients (34.6\%) had a pure motor form, and 2 patients (1.3\%) had MFS. Approximately, one-fourth of the patients needed mechanical ventilation, and $16.0 \%$ needed tracheostomy. The median duration of ICU stay was 17.5 (7.5-34.5) days.

\section{Investigations and electrophysiological subtypes}

CSF analysis was performed in $123(78.8 \%)$ patients, at a median of 5 (IQR, 2-14) days after symptom onset, and "cytoalbuminological dissociation" was observed in 85 (69.1\%) patients.

(Table 2). CSF protein concentration was increased in $44(59.5 \%)$ patients at $<8$ days, $19(82.6 \%)$ patients at 8 - 14 days, and $22(84.6 \%)$ patients at $>14$ days after disease onset. FVC was available from $84(53.8 \%)$ patients at admission. Less than a third of these patients had a low FVC, defined as FVC $<1.5 \mathrm{~L}$ or $20 \mathrm{~mL} / \mathrm{kg}$. Nerve root enhancement was observed in $32(42.7 \%)$ of the 75 patients who had spinal cord magnetic resonance imaging. Nerve conduction study (NCS) reports were available from $146(93.6 \%)$ patients, and the procedure was performed at a median of 10 (IQR 5-20) days after symptom onset. Of these patients, $55(37.7 \%)$ were considered to have AIDP, 43 (29.5\%) were considered to have AMAN, 28 (19.2\%) were considered to have AMSAN, and $9(6.2 \%)$ were considered as equivocal, Table 2.

\section{Therapy and outcome}

GBS-specific therapy was administered in 151 (96.8\%) patients at a median duration of 7 (IQR, 4-13.75) days after symptom onset (Table 2). The majority of these patients (88.1\%) had intravenous immunoglobulin (IVIg), and the remainder (11.9\%) had plasmapheresis. A quarter of these patients had a second course of therapy at a median duration of 17 (IQR, 8.5-28.5) days after completion of the first therapy. The median duration of hospitalization for the 145 (93\%) patients with available data was 2.4 (1-8) weeks. Ability to walk was reported at follow-up in 97 (62.2\%) patients. Approximately half of 
Table 2 Laboratory and electrophysiological features, therapy, and outcome of patients with GBS

\begin{tabular}{|c|c|}
\hline Variable & $\mathrm{N}(\%)$ or median (IQR) \\
\hline $\mathrm{CSF}^{\mathrm{a}}$ & $123(78.8)$ \\
\hline Protein level, g/L & $0.63(0.39-1.13)$ \\
\hline Protein $>0.45 \mathrm{~g} / \mathrm{L}$ & $85(69.1)$ \\
\hline Cell count/ $\mu$ l & $1.0(0-3)$ \\
\hline Cell count $>5 / \mu l$ & $13(10.6)$ \\
\hline Cytoalbuminological dissociation & $85(69.1)$ \\
\hline Low FVC $(<1.5 \mathrm{~L}$ or $20 \mathrm{~mL} / \mathrm{kg})$ at admission & 23/84 (27.4) \\
\hline MRI spine: root enhancement & $32 / 75(42.7)$ \\
\hline MRI brain: cranial nerve enhancement & $2 / 76(2.6)$ \\
\hline Electrophysiological subtypes as reported ${ }^{b}$ & $146(93.6)$ \\
\hline AIDP & $55 / 146(37.7)$ \\
\hline AMAN & $43 / 146(29.5)$ \\
\hline AMSAN & 28/146 (19.2) \\
\hline Equivocal & $9 / 146(6.2)$ \\
\hline Normal & $11 / 146(7.5)$ \\
\hline Received GBS Therapy ${ }^{c}$ & $151(96.8)$ \\
\hline $\mathrm{IVlg}$ & 133/151 (88.1) \\
\hline PLEX & 18/151 (11.9) \\
\hline Repeated therapy ${ }^{d}$ & $38 / 151(25.2)$ \\
\hline IVlg-PLEX & 19/38 (50.0) \\
\hline IVlg-IVlg & $11 / 38(28.9)$ \\
\hline PLEX-IVlg & $7 / 38(18.4)$ \\
\hline PLEX-PLEX & $1 / 38(2.6)$ \\
\hline Duration of hospitalization ( $N=145,93 \%)$ & $2.4(1-8)$ weeks \\
\hline Outcome at follow-up & $97(62.2 \%)$ \\
\hline Able to walk independently at $<6$ months & $37 / 97(38.1)$ \\
\hline Able to walk independently at $6-9$ months & $11 / 97(11.3)$ \\
\hline Able to walk independently at $>9$ months & $32 / 97(33.0)$ \\
\hline Able to walk with support at $>9$ months & 10/97 (10.3) \\
\hline Unable to walk at $>9$ months & $7 / 97(7.2)$ \\
\hline Died (Septicemia) & $1 / 156(0.64)$ \\
\hline
\end{tabular}

AIDP acute inflammatory demyelinating polyradiculoneuropathy, AMAN acute motor axonal neuropathy, AMSAN acute motor-sensory axonal neuropathy, IVIg intravenous immunoglobulin, MFS Miller-Fisher syndrome, $N$ number of patients for whom data are available, PLEX plasma exchange

${ }^{a}$ Median time after the onset of symptoms $=5(2-14)$ days, and maximum CSF cell count $=23$ cells $/ \mu \mathrm{l}$

${ }^{\mathrm{b}}$ Median time after the onset of symptoms $=10$ (5-20) days

'Median time after the onset of symptoms $=7$ (4-13.75) days

${ }^{\mathrm{d}}$ Median time after first therapy $=17(8.5-28.5)$ days

these patients were able to walk independently within 9 months after discharge, and a third regained the ability to walk independently thereafter. Death of one patient was caused by septicemia.

\section{Comparison between GBS subtypes}

Comparisons between GBS subtypes are shown in Tables 3 and 4 . There were no significant differences in the clinical features between the GBS subtypes with the exception that there was a higher proportion of patients who were able to walk independently at the time of admission in the AIDP subtype compared to that in the axonal subtype (combined AMAN and AMSAN). Patients with AMSAN were significantly more likely to have oropharyngeal weakness than those with AMAN. An antecedent URTI was more frequent in patients with AIDP compared to those with the axonal subtype, and diarrhea was more frequent in patients with AMAN compared to those with AMSAN. CSF protein level was significantly lower in patients with AMAN (median, $0.5 \mathrm{~g} / \mathrm{L} ; \mathrm{IQR}, 0.32-0.86)$ than in patients with AIDP (median, $0.8 \mathrm{~g} / \mathrm{L}$; IQR, 0.51-1.4; Bonferroni-corrected $P=0.05$ ) and AMSAN (median $0.93 \mathrm{~g} / \mathrm{L}$; IQR, 0.59-2.4; Bonferroni-corrected $P=0.036$ ).

Regarding hospital course, there were more frequent repeated therapy, ICU admission, mechanical ventilation, and tracheostomy and longer duration of hospitalization in patients with the axonal subtype compared to those with AIDP, Table 3. These variables and duration of ICU stay were also more frequent in patients with AMSAN compared to those in patients with AMAN, Table 4. Despite the shorter follow-up period in patients with AIDP, a higher proportion of these patients were able to walk independently at follow-up compared to those with the axonal subtype.

\section{Discussion}

This is the first nationwide multicenter study on adult patients with GBS in Saudi Arabia. The earliest studies included a small number of patients recruited from a single center $[10,15,16]$. A previous local study in the $1990 \mathrm{~s}$ [10] showed that GBS is more predominant in men than women in the third and fourth decades. In contrast, there has been a remarkable attenuation in men to women ratio whereby it decreased from the 9:1 ratio in a previous local study [10] to 2.4:1 in this study. The predominance of GBS in men is consistent with those in previous regional and international studies $[5,8,14,17-22]$. A meta-analysis revealed that the incidence of GBS increases with age [23], and this has also been reported in the international GBS outcome study (IGOS) that included 925 patients worldwide [5]. In contrast, only $18.6 \%$ of our patients were in the older age group. This discrepancy in the age distribution between our cohort and international studies may be explained by variations in the demography of the general populations. In the 2019 census, only 5.5\% of the Saudi population was 60 years and older [24], reflecting a lower number of persons at risk in this age category compared to the younger age categories.

Literature review revealed that two-thirds of patients with GBS have an antecedent respiratory or 
Table 3 Clinical and laboratory characteristics and outcome comparing axonal versus demyelinating subtypes of GBS

\begin{tabular}{|c|c|c|c|c|}
\hline \multirow[t]{2}{*}{ Variable } & \multirow{2}{*}{$\begin{array}{l}\text { Axonal (AMAN and } \\
\text { AMSAN), }(N=71) \\
N(\%) \text { or Median (IQR) }\end{array}$} & \multirow{2}{*}{$\begin{array}{l}\text { Demyelinating (AIDP) }(N=55) \\
N(\%) \text { or Median (IQR) }\end{array}$} & \multirow[t]{2}{*}{$P$-value } & \multirow[t]{2}{*}{ OR $(95 \% \mathrm{Cl})$} \\
\hline & & & & \\
\hline Age, years & $38(26-54)$ & $39(28-50)$ & 0.88 & \\
\hline Sex (men) & $40 / 71(56.3)$ & $36 / 55(65.6)$ & 0.30 & \\
\hline Time of antecedent event before symptom onset, days & $10(7-14)$ & $14(7-21)$ & 0.14 & \\
\hline Time from symptom onset to presentation, days & $6(2-13)$ & $7(4-14)$ & 0.043 & \\
\hline \multicolumn{5}{|l|}{ Clinical features at admission } \\
\hline Ophthalmoplegia & $3 / 68(4.4)$ & $3 / 55(5.5)$ & 1.0 & \\
\hline Facial diplegia & $27 / 68(39.7)$ & 28/55 (50.9) & 0.21 & \\
\hline Oropharyngeal weakness & $24 / 69(34.8)$ & $17 / 55(30.9)$ & 0.65 & \\
\hline Able to walk independently & $16 / 68(23.5)$ & $25 / 53(47.2)$ & 0.006 & $2.9(1.3-6.3)$ \\
\hline \multicolumn{5}{|l|}{ Antecedent infection } \\
\hline URTI & $15 / 64(23.4)$ & $27 / 50(54.0)$ & 0.001 & $3.8(1.7-8.6)$ \\
\hline Diarrhea & $27 / 64(42.2)$ & $9 / 50(18.0)$ & 0.006 & $3.3(1.4-8.0)$ \\
\hline \multicolumn{5}{|l|}{ Investigations } \\
\hline CSF protein level, g/L & $0.65(0.39-1.1)$ & $0.8(0.51-1.4)$ & $0.27^{*}$ & \\
\hline CSF protein $>0.45 \mathrm{~g} / \mathrm{L}$ & $38 / 57(66.7)$ & $35 / 44(79.5)$ & 0.15 & \\
\hline Cell count $>5 / \mu l$ & $3 / 57(5.3)$ & $4 / 44(9.1)$ & 0.70 & \\
\hline Low FVC & $13 / 39(33.3)$ & $9 / 34(26.5)$ & 0.52 & \\
\hline Nerve root enhancement on MRI & $16 / 52(30.8)$ & 10/34 (29.4) & 0.89 & \\
\hline \multicolumn{5}{|l|}{ Hospital course } \\
\hline Repeated therapy & 23/68 (33.8) & $8 / 53(15.1)$ & 0.019 & $2.9(1.2-7.1)$ \\
\hline ICU admission & $30 / 71(42.3)$ & $12 / 54(22.2)$ & 0.019 & $2.6(1.2-5.7)$ \\
\hline Mechanical ventilation & $26 / 58(44.8)$ & $8 / 48(16.7)$ & 0.002 & $4.1(1.6-10.2)$ \\
\hline Tracheostomy & $17 / 56(30.4)$ & $3 / 47(6.4)$ & 0.002 & $6.4(1.7-23.5)$ \\
\hline Duration of ICU stay, days & $28(15-70)$ & $12(7-19.5)$ & 0.10 & \\
\hline Duration of hospitalization, weeks & $4(1.4-13.8)$ & $2(1-4)$ & 0.003 & \\
\hline \multicolumn{5}{|l|}{ Outcome } \\
\hline Able to walk independently at follow-up & $38 / 53(71.7)$ & $38 / 43(88.4)$ & 0.045 & $3(1.0-9.1)$ \\
\hline Duration of follow-up, months & $11(4.6-17.4)$ & $5(2-12)$ & 0.03 & \\
\hline
\end{tabular}

${ }^{*}$ CSF protein level was higher in AIDP than in AMAN (median, $0.5 ; \mathrm{IQR}, 0.32-0.86$ ), Bonferroni-corrected $P=0.05$

gastrointestinal tract infection in the 6 weeks preceding the onset of GBS [1]. In our study, $66.9 \%$ of the patients had an URTI or diarrhea with a median time of 12 days before symptom onset. Compared to other GBS subtypes, we observed an association between antecedent URTI and AIDP and between antecedent diarrhea and AMAN, which is consistent with data from previous studies [14, 22, 25].

Although the diagnosis of GBS is based on the clinical criteria, CSF examination is required to substantiate the diagnosis and exclude competing diagnoses such as infectious or neoplastic polyradiculitis. The typical CSF finding in GBS is cytoalbuminological dissociation [11]. Concurring with previous studies $[5,12,26]$, CSF protein level was highly dependent on the timing of lumbar puncture. The proportion of patients with an elevated CSF protein level was lower in the first week compared to that in the second and third week after symptom onset.
Of all patients, 69.1\% had an elevated CSF protein level. This was higher than that reported in the Asian cohort (56\%) [26], and similar to that reported in the Dutch $(64 \%)$ and IGOS $(68 \%)$ cohorts $[5,12]$. The proportion of patients with mild pleocytosis, defined as a CSF cell count of 5 - 50 cells/ $\mu$ l was lower in this study (10.6\%) than that reported in the Asian (26\%), Dutch (15\%) and IGOS (19\%) cohorts $[5,12,26]$. Because no patient had a CSF cell count $>50$ cells $/ \mu \mathrm{l}$, "cytoalbuminological dissociation" was determined by elevated CSF protein level, and observed in $69.1 \%$ of the patients in this study, compared to $55 \%$ in the Asian cohort [26], 64\% in the Dutch cohort [12], and $67 \%$ in the IGOS cohort [5]. The difference in CSF protein levels between this study and the Asian study is not explained by the timing of lumbar puncture because similar proportions of patients in both studies had lumbar puncture in the first $(60 \%)$ and second week (20\%) after symptom onset. It is possible that a variability 
Table 4 Clinical and laboratory characteristics and outcome comparing AMAN versus AMSAN subtypes of GBS

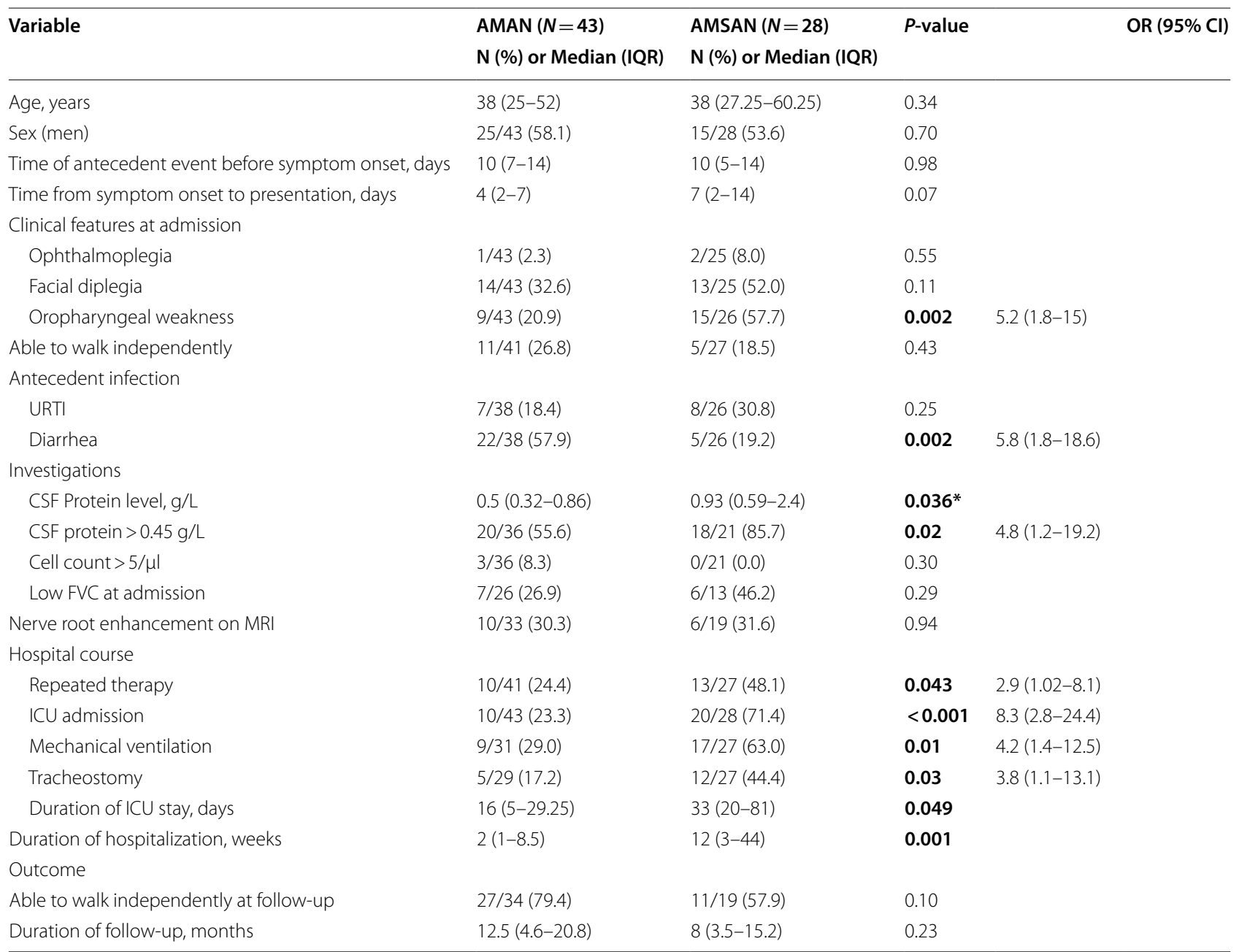

*Bonferroni-corrected

in the proportions of GBS subtypes could have contributed to this discrepancy, although this hypothesis cannot be evaluated because GBS subtypes were not provided in the Asian cohort. For example, we observed a higher CSF protein level in patients with AIDP and AMSAN compared to that in patients with AMAN. This supports the findings of a recent study that reported a higher CSF protein in the sensorimotor and demyelinating subtypes compared to the pure motor and axonal subtypes [27]. The relatively lower CSF protein in patients with AMAN may be related, in part, to the selective targeting of the nodal/paranodal region, as opposed to the involvement of sensory and motor nerve roots in AIDP [6].

In this study, the AIDP was the most commonly reported electrophysiological subtype, accounting for $37.7 \%$ of the GBS cases. The second and third prevalent subtypes were AMAN and AMSAN, accounting for $29.5 \%$ and $19.2 \%$ of the cases, respectively. The corresponding proportions in a cohort of 44 patients from Oman were 52\% for AIDP, 30\% for AMAN, and 14\% for AMSAN [17]. These two timely studies from the Arabian Peninsula showed similar predominance of the GBS subtypes, although the proportions of patients with AIDP were relatively lower in this study compared to those in the Omani study. A relatively older study from Kuwait reported a higher proportion of AIDP (68\%) and a lower proportion of the axonal subtype (15\%) [8]. Two recent retrospective studies from Northern and Southern China reported different frequencies of the electrophysiological subtypes of GBS. In the former study, AMAN was the predominant subtype (55.8\%) and AIDP occurred less frequently (21.2\%) [22], whereas the study from Southern China reported a relatively higher frequency of AIDP (49.0\%) compared to a lower frequency of AMAN (18.8\%) [28]. The proportions of GBS subtypes in this study are relatively comparable to data from Southern 
China [28]. However, the frequency of AMAN in China and Saudi Arabia is still higher than that reported from North America and Europe (3.0\%) [3]. The geographic discrepancies in the incidence of AMAN and AIDP may be influenced by environmental factors, differences in the frequencies and types of preceding infections, and genetic polymorphisms of Campylobacter jejuni strains. The relative similarity between our data and data from Southern China [28], representing two different ethnic groups, argues against a role for human genetic polymorphisms in influencing GBS subtype.

Overall, despite the prolonged recovery time and residual weakness in some patients, the outcome in our cohort is favorable. The ability to walk independently within 6 months was achieved in a lower proportion of patients in our cohort (38.1\%) compared to that at 6 months in the IGOS cohort (77\%). This discrepancy was due to the retrospective nature of our study wherein follow-up visits were not conducted at fixed time points. Nonetheless, the proportions of patients who were able to walk independently were very similar when comparing our data at $>9$ months $(82.5 \%)$ to the IGOS cohort at 12 months (81\%) [5]. In agreement with the literature [5], our data showed that the ability to walk independently at followup was achieved in a higher proportion of patients with AIDP than those with the axonal subtype.

The need for mechanical ventilation has been reported in $20 \%-30 \%$ of patients with GBS [12]. Likewise, approximately one-fourth of our patients required mechanical ventilation. Contradicting the report by Durand et al., who observed that the risk of requiring mechanical ventilation was higher in patients with demyelinating neuropathy [29], we observed that a high proportion of patients with the axonal subtype, particularly AMSAN, required mechanical ventilation and subsequent tracheostomy. This was reflected on a longer duration of hospitalization in the axonal subtype compared to the AIDP. Among the patients with axonal subtype, a higher proportion of patients with AMSAN needed mechanical ventilation and had longer duration of ICU stay and hospitalization than those with AMAN.

\section{Limitations}

The inherent limitations of retrospective studies are to be considered when interpreting the findings of this study, including the bias introduced by missing data, lack of standard assessment, and differences in timing of follow-up. The retrospective and multicentric nature of the study and the lack of availability of NCS raw data hindered our ability to independently confirm the GBS subtypes documented by the treating neurologist at each hospital. Antiganglioside antibodies were not included because these were not tested in almost all centers.

\section{Conclusions}

The clinical and laboratory characteristics of patients with GBS in Saudi Arabia and their outcome are similar to those in the international cohorts. The reported GBS subtypes in order of frequency are AIDP, AMAN, and AMSAN. A prospective study with more rigorous data collection will aid in evaluating the incidence and burden of the disease nationwide.

\section{Abbreviations \\ AIDP: Acute inflammatory demyelinating polyradiculoneuropathy; AMAN: Acute motor axonal neuropathy; AMSAN: Acute motor-sensory axonal neuropathy; GBS: Guillain-Barre syndrome; ICU: Intensive care unit; IGOS: International Guillain-Barre'Syndrome Outcome Study; IVIg: Intravenous immunoglobulin; MFS: Miller-Fisher syndrome; NCS: Nerve conduction stud- ies; PLEX: Plasmapheresis.}

\section{Acknowledgements}

The authors thank the Deanship of Scientific Research and RSSU at King Saud University for their technical support.

\section{Ethical publication statement}

We confirm that we have read the journal's position on issues involved in ethical publication and affirm that this report is consistent with those guidelines.

\section{Authors' contributions}

M.H.A was involved in study conception and design, analysis of results, data interpretation, supervision of data acquisition, and writing the manuscript. S.S.B was involved in data acquisition, data interpretation, and writing and review of the manuscript. A.A, N.S.A, N.A, R.A.M, A.M.O, T.M.A, S.O.A, A.C.A, Y.A, A.S.A, S.M, A.M, L.A, F.A, M.A, A.K.B, A.A.A, and A.R.A were involved in data acquisition, data interpretation, and review of the manuscript. All authors reviewed and approved the final version of the manuscript.

\section{Funding}

This work was supported by the College of Medicine Research Center, Deanship of Scientific Research, King Saud University, Riyadh, Saudi Arabia (funding grant number E-19-3880).

\section{Availability of data and materials}

Data and relevant material is available upon request. However, access to the data is restricted to the public and require appropriate approvals from the authorized and participating parties.

\section{Declarations}

\section{Ethics approval and consent to participate}

The study was conducted in accordance with the principles of the Declaration of Helsinki. All methods followed the relevant guidelines and regulations. The study was approved by the institutional review board at King Saud University and all other participating centers (Security Forces Hospital, Prince Sultan Military Medical City, King Fahad Medical City, King Fahad Specialist Hospital-Dammam, King Fahad Hospital of the University, King Saud Bin Abdulaziz University for Health Sciences, King Abdulaziz University). Because of the retrospective nature of the study, the need for informed consent was waved by the Institutional Review Board at King Saud University and all other participating centers.

Consent for publication Not applicable. 


\section{Competing interests}

All authors declare that they have no competing interests.

\section{Author details}

${ }^{1}$ Division of Neurology, Department of Internal Medicine, King Saud University Medical City and College of Medicine, King Saud University, Riyadh, Saudi Arabia. ${ }^{2}$ College of Medicine, King Saud University, Riyadh, Saudi Arabia. ${ }^{3}$ Department of Medicine, Security Forces Hospital Program, Riyadh, Saudi Arabia. ${ }^{4}$ Department of Neurology, Prince Sultan Military Medical City, Riyadh, Saudi Arabia. ${ }^{5}$ Neurology Department, Neuroscience Center, King Fahad Specialist Hospital-Dammam, Dammam, Saudi Arabia. ${ }^{6}$ Neurology Department, National Neuroscience Institute, King Fahad Medical City, Riyadh, Saudi Arabia. ${ }^{7}$ College of Medicine, King Saud Bin Abdulaziz University for Health Sciences, Jeddah, Saudi Arabia. ${ }^{8}$ King Abdullah International Medical Research Center, Jeddah, Saudi Arabia. ${ }^{9}$ Department of Medicine, Ministry of the National Guard-Health Affairs, Jeddah, Saudi Arabia. ${ }^{10}$ Department of Neurology, King Fahad Hospital of the University, Imam Abdulrhman Bin Faisal University, Dammam, Saudi Arabia. ${ }^{11}$ Internal Medicine Department, Neurology Division, Neuromuscular Medicine Unit, Faculty of Medicine and King Abdulaziz University Hospital, King Abdulaziz University, Jeddah, Saudi Arabia. ${ }^{12}$ Pediatric department, Neuromuscular Medicine Unit, Faculty of Medicine and King Abdulaziz University Hospital, King Abdulaziz University, Jeddah, Saudi Arabia.

Received: 7 February 2021 Accepted: 30 June 2021

Published online: 12 July 2021

\section{References}

1. Leonhard SE, Mandarakas MR, Gondim FAA, Bateman K, Ferreira MLB, Cornblath DR, et al. Diagnosis and management of Guillain-Barré syndrome in ten steps. Nat Rev Neurol. 2019;15:671-83.

2. Créange A. Guillain-Barré syndrome: 100 years on. Rev Neurol (Paris). 2016;172:770-4.

3. Hadden RD, Cornblath DR, Hughes RA, Zielasek J, Hartung HP, Toyka KV, et al. Electrophysiological classification of Guillain-Barré syndrome: clinical associations and outcome. Plasma Exchange/Sandoglobulin GuillainBarré Syndrome Trial Group. Ann Neurol. 1998;44:780-8.

4. Malek E, Salameh J. Guillain-Barre Syndrome. Semin Neurol. 2019;39:589-95.

5. Doets AY, Verboon C, van den Berg B, Harbo T, Cornblath DR, Willison $\mathrm{HJ}$, et al. Regional variation of Guillain-Barré syndrome. Brain J Neurol. 2018;141:2866-77.

6. Dimachkie MM, Barohn RJ. Guillain-Barré syndrome and variants. Neurol Clin. 2013;31:491-510.

7. Benamer HTS, Bredan A. Guillain-Barré syndrome in Arab countries: a systematic review. J Neurol Sci. 2014;343:221-3.

8. Nagarajan V, Al-Shubaili A. Clinical and neurophysiological pattern of Guillain-Barré syndrome in Kuwait. Med Princ Pract Int J Kuwait Univ Health Sci Cent. 2006;15:120-5.

9. Ansari B, Basiri K, Derakhshan Y, Kadkhodaei F, Okhovat AA. Epidemiology and Clinical Features of Guillain-Barre Syndrome in Isfahan. Iran Adv Biomed Res. 2018;7:87.

10. Bahou YG, Biary N, al Deeb S. Guillain-Barre syndrome: a series observed at Riyadh Armed Forces Hospital January 1984--January 1994. J Neurol. 1996;243:147-52.

11. Sejvar JJ, Kohl KS, Gidudu J, Amato A, Bakshi N, Baxter R, et al. GuillainBarré syndrome and Fisher syndrome: case definitions and guidelines for collection, analysis, and presentation of immunization safety data. vaccine. 2011;29:599-612.
12. Fokke C, van den Berg B, Drenthen J, Walgaard C, van Doorn PA, Jacobs BC. Diagnosis of Guillain-Barré syndrome and validation of Brighton criteria. Brain J Neurol. 2014;137:33-43.

13. Yuki N, Hartung H-P. Guillain-Barré syndrome. N Engl J Med. 2012;366:2294-304

14. Zeng Y, Liu Y, Xie Y, Liang J, Xiao Z, Lu Z. Clinical Features and the Validation of the Brighton Criteria in Guillain-Barré Syndrome: Retrospective Analysis of 72 Hospitalized Patients in Three Years. Eur Neurol. 2019;81:231-8.

15. Abduljabbar MS. Pattern of Guillain-Barré syndrome in Saudi Arabia. J Trop Geogr Neurol. 1991;1:35-8.

16. Dahbour SS. Clinical Experience with Gullain Barre Syndrome Over a 6-Year Period in One Hospital in The Middle East. Jordan Med J. 2010;43. https://journals.ju.edu.jo/JMJ/article/view/936. Accessed 21 May 2021.

17. Al Maawali SM, AI Shibani AY, Nadeem AS, Al-Salti AM. Guillain-Barre syndrome: demographics, clinical features, and outcome in a single tertiary care hospital. Oman Neurosci Riyadh Saudi Arab. 2020;25:369-74.

18. Alzaidi MA, Nouri KA. Guillain-Barre syndrome. Pattern of muscle weakness. Neurosci Riyadh Saudi Arab. 2002;7:176-8.

19. Arami MA, Yazdchi M, Khandaghi R. Epidemiology and characteristics of Guillain-Barré syndrome in the northwest of Iran. Ann Saudi Med. 2006;26:22-7.

20. Mitsui Y, Kusunoki S, Arimura K, Kaji R, Kanda T, Kuwabara S, et al. A multicentre prospective study of Guillain-Barré syndrome in Japan: a focus on the incidence of subtypes. J Neurol Neurosurg Psychiatry. 2015;86:110-4.

21. Beydoun HA, Beydoun MA, Hossain S, Zonderman AB, Eid SM. Nationwide study of therapeutic plasma exchange vs intravenous immunoglobulin in Guillain-Barré syndrome. Muscle Nerve. 2020;61:608-15.

22. Tian J, Cao C, Li T, Zhang K, Li P, Liu Y, et al. Electrophysiological Subtypes and Prognostic Factors of Guillain-Barre Syndrome in Northern China. Front Neurol. 2019;10:714.

23. Sejvar JJ, Baughman AL, Wise M, Morgan OW. Population incidence of Guillain-Barré syndrome: a systematic review and meta-analysis. Neuroepidemiology. 2011;36:123-33.

24. Population by age groups and gender.pdf. General Authority for Statistics. 2019. https://www.stats.gov.sa/sites/default/files/population_by_age_ groups_and_gender_en.pdf. Accessed 21 May 2021.

25. Ye Y, Wang K, Deng F, Xing Y. Electrophysiological subtypes and prognosis of Guillain-Barré syndrome in northeastern China. Muscle Nerve. 2013;47:68-71.

26. Wong AHY, Umapathi T, Nishimoto Y, Wang YZ, Chan YC, Yuki N. Cytoalbuminologic dissociation in Asian patients with Guillain-Barré and Miller Fisher syndromes. J Peripher Nerv Syst. 2015;20:47-51.

27. Bourque PR, Brooks J, Warman-Chardon J, Breiner A. Cerebrospinal fluid total protein in Guillain-Barré syndrome variants: correlations with clinical category, severity, and electrophysiology. J Neurol. 2020;267:746-51.

28. Liu S, Xiao Z, Lou M, Ji F, Shao B, Dai H, et al. Guillain-Barré syndrome in southern China: retrospective analysis of hospitalised patients from 14 provinces in the area south of the Huaihe River. J Neurol Neurosurg Psychiatry. 2018;89:618-26.

29. Durand M-C, Porcher R, Orlikowski D, Aboab J, Devaux C, Clair B, et al. Clinical and electrophysiological predictors of respiratory failure in Guillain-Barré syndrome: a prospective study. Lancet Neurol. 2006;5:1021-8.

\section{Publisher's Note}

Springer Nature remains neutral with regard to jurisdictional claims in published maps and institutional affiliations. 